
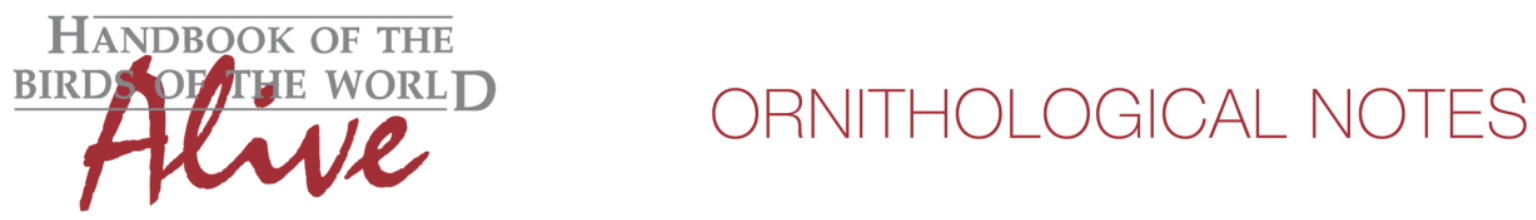

\title{
Notes on the vocalizations of Tropical Gnatcatcher (Polioptila plumbea)
}

Peter Boesman

In the following we briefly analyze and compare voice of the different races of Tropical Gnatcatcher (Polioptila plumbea). We also try to quantify the extent of any vocal differences using the criteria proposed by Tobias et al. (2010), as a support for taxonomic review. We have made use of sound recordings available on-line from Xeno Canto (XC)

A comparison of songs:

"bilineata group" (including superciliaris, brodkorbi and cinericia) (Central America and West of Andes)

Example of typical song:

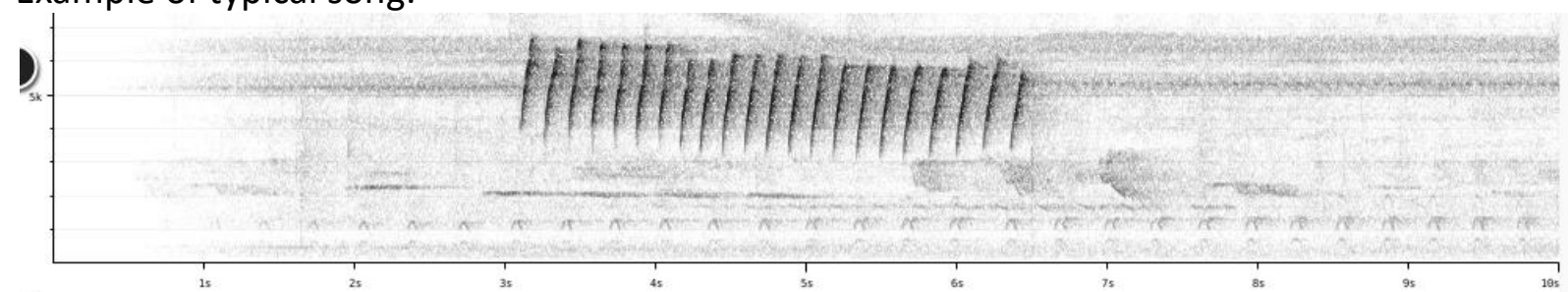

Song is a series of short, identical notes. Pace and duration varies, but note shape always steeply upslurred. Note series is at about constant pitch or slightly descending in pitch $(n=20+)$.

"nominate group" (with anteocularis, daguae, innotata, parvirostris, plumbiceps and atricapilla)(Northern South America East of the Andes)

Song structuraly similar to previous group, but with a much higher variability in song. Some subspecies (e.g. plumbiceps) show remarkable variability within the same race, other races however have a more uniform song (e.g.parvirostris).

Both groups share however the typical song of a series of more or less identical notes. Some examples of race plumbiceps:

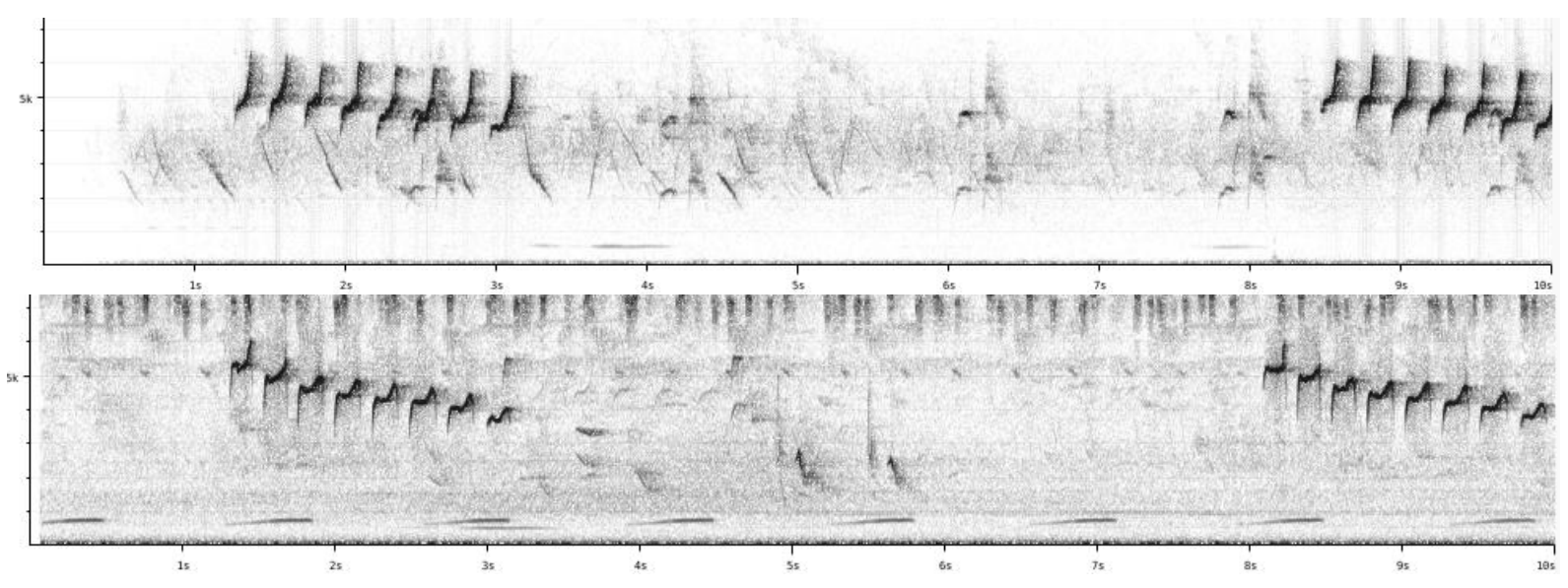




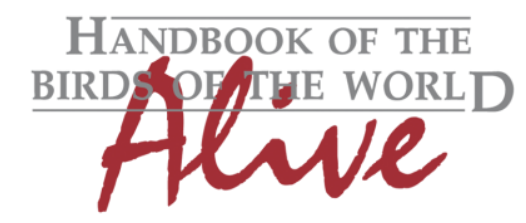

\section{ORNITHOLOGICAL NOTES}

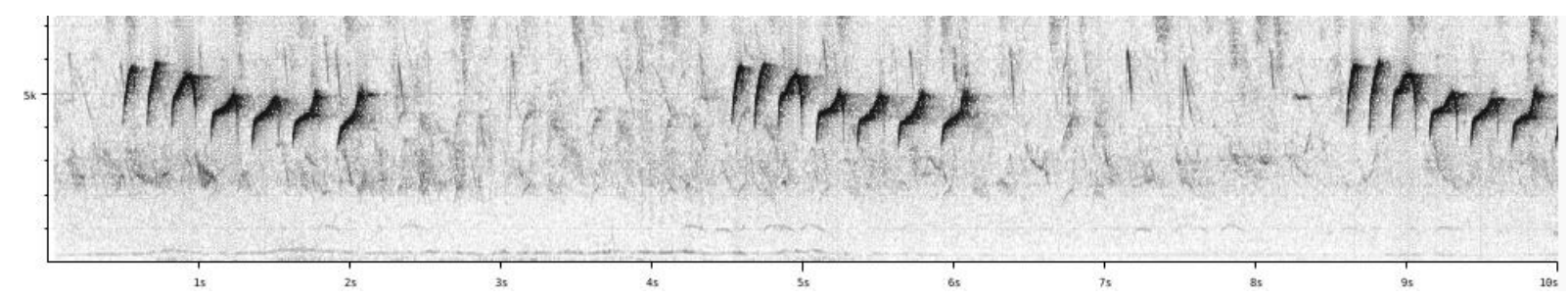

"maior group" (Marañon Gnatcatcher):

Presumed song consists of a mixture of the typical nasal whining calls with more melodious whistles, having more the aspect of a warble (and thus more close to song of e.g. Whitelored Gnatcatcher P. albiloris of Central America).
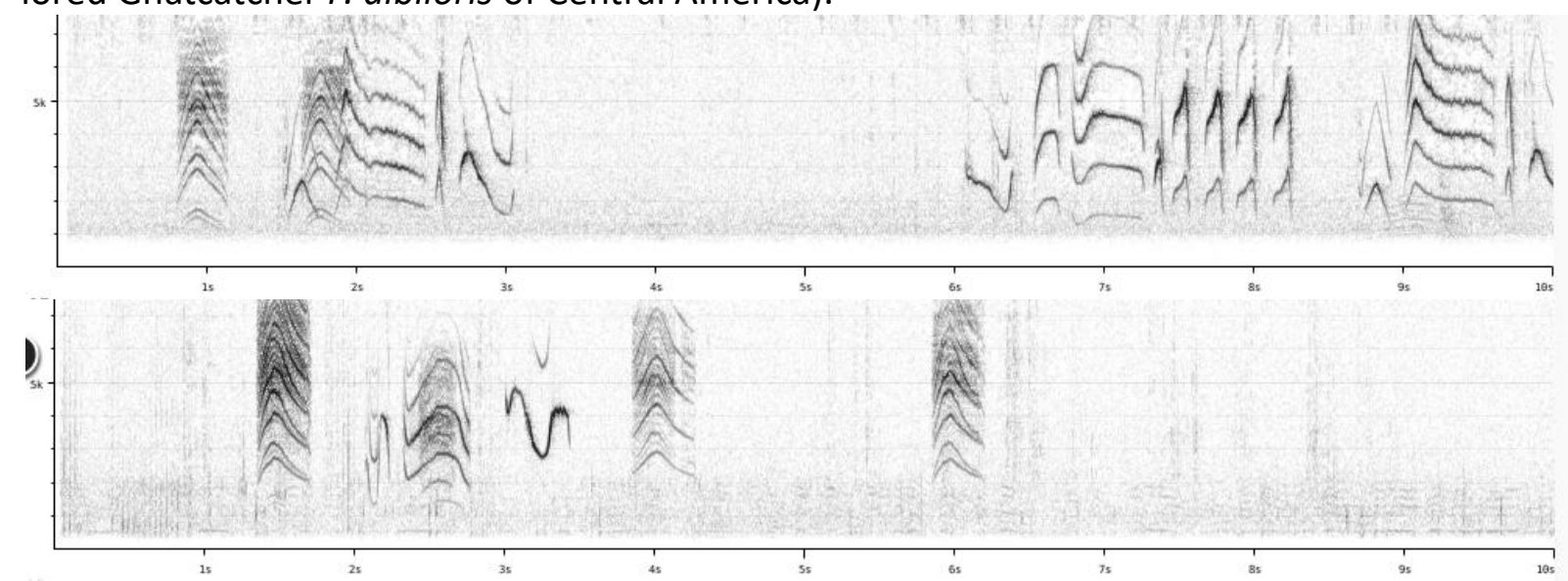

Despite the high variability of many races, maior is thus really standing apart.

Vocal difference could be quantified based on e.g. lower \# notes repeated (2-3), slower pace (3), lower min. freq. (3), higher \# of different notes per song phrase (3), higher max. length of notes (3), leading to a total vocal score of about 6 when applying Tobias criteria.

It should be noted that this assessment is based on just a few available recordings of song of race maior, but supported by voice description in literature (Schulenberg et al. 2007).

This note was finalized on 14th April 2016, using sound recordings available on-line at that moment. We would like to thank in particular the many sound recordists who placed their recordings for this species on XC.

\section{References}

Schulenberg T.S., Stotz, D.F., Lane D.F., O'Neil J.P. \& Parker, T.A. (2007) Birds of Peru. Princeton Field Guide. Princeton University Press. Princeton and London.

Tobias, J.A., Seddon, N., Spottiswoode, C.N., Pilgrim, J.D., Fishpool, L.D.C. \& Collar, N.J.

(2010). Quantitative criteria for species delimitation. Ibis 152(4): 724-746. 


\section{Recommended citation}

Boesman, P. (2016). Notes on the vocalizations of Tropical Gnatcatcher (Polioptila plumbea). HBW Alive Ornithological Note 280. In: Handbook of the Birds of the World Alive. Lynx Edicions, Barcelona. (retrieved from http://www.hbw.com/node/1251721 on 11 October 2016). 